\title{
Analysis on the B2C E-Commerce Pattern in China
}

\author{
Yingyao Shi \\ Department of Tourism Management, Management School, Jinan University, Guangzhou, China \\ Email: shiyingyao.susan@foxmail.com
}

How to cite this paper: Shi, Y.Y. (2016) Analysis on the B2C E-Commerce Pattern in China. Journal of Service Science and Management, 9, 443-452. http://dx.doi.org/10.4236/jssm.2016.95048

Received: October 3, 2016

Accepted: October 25, 2016

Published: October 28, 2016

Copyright $\odot 2016$ by author and Scientific Research Publishing Inc. This work is licensed under the Creative Commons Attribution International License (CC BY 4.0).

http://creativecommons.org/licenses/by/4.0/ (c) (†) Open Access

\begin{abstract}
With the development of science and technology, the Internet is growing increasingly popular with the Chinese people. Accompany with the increment of online consumers groups, an increasing number of traditional enterprises have introduced the electronic commerce mode. This paper is intended to make a preliminary analysis of the $\mathrm{B} 2 \mathrm{C}$ electronic commerce pattern. At first, it will introduce the concept of the $\mathrm{B} 2 \mathrm{C}$ electronic commerce pattern and the necessity for companies to use the B2C electronic commerce pattern. Then, the development of the $\mathrm{B} 2 \mathrm{C}$ electronic commerce in China will be described. After that, it will focus on the four patterns of the B2C electronic commerce including the E-commerce Direct Selling Pattern, the Integrated Middlemen Pattern, the Vertical Middlemen Pattern and the Third-party Trading Platform Pattern. Finally, suggestions will be given to future development of the $\mathrm{B} 2 \mathrm{C}$ e-commerce in China based on the analysis.
\end{abstract}

\section{Keywords}

B2C, Electronic Commerce, Business Pattern

\section{Introduction}

At present, various types of e-commerce platforms offer all sorts of products and services. The companies adopting $\mathrm{B} 2 \mathrm{C}$ electronic commerce pattern could achieve competitive advantages. In the long run, the $\mathrm{B} 2 \mathrm{C}$ e-commerce will achieve double-quick development and occupy the main position of e-commerce field finally. This paper will describe the $\mathrm{B} 2 \mathrm{C}$ electronic commerce in China and summarize the characteristics of the four B2C e-commerce patterns. Consequently, recommendations for future development of the $\mathrm{B} 2 \mathrm{C}$ e-commerce in China were put forth.

\section{The Concept of the B2C Electronic Commerce Pattern}

B2C is short for Business to Customer, which refers to all the trade activities online. In 
all these cases, companies create a chain connecting information flows, capital flows, trade flows and part of the logistics completely. The B2C electronic commerce allows enterprises or business institutions to make full use of information networks and electronic data information to conduct business activities, trading activities, financial activities and integrated service activities with customers. It is also a form of direct participation in economic activities with the Internet for customers [1]. According to the services provided for the customers, the $\mathrm{B} 2 \mathrm{C}$ electronic commerce pattern can be divided into electronic brokerage, online direct marketing, electronic retail, distance education, online entertainment, online booking, online issue, e-finance and so on [2]. Electronic brokerage allows customers to buy and sell stocks and get investment information from the websites. Online direct marketing refers to the manufacturers cut out the middleman and sell product to the customers directly. Electronic retail refers to the enterprises offer retail service by electrical means including the Internet, mobile phone, digital television and radio. Distance education is an education mode implemented through video and audio by using computer science techniques including real-time and non-real time applications. E-finance is similar with electronic retail in which the enterprises provide financial service online including network banking transaction, network securities business and network insurance business. The main profit sources of the $\mathrm{B} 2 \mathrm{C}$ electronic commerce include sales profits, service charges, advertising revenues, initial income and membership fees income [3].

\section{The Necessity for Companies to Introduce the B2C Electronic Commerce Pattern}

The B2C electronic commerce pattern is nearly equal to online stores or online retail stores. The pattern mainly impacts the downstream of the value chain, namely the connection between the companies and the final customers. In traditional value chain, the products have to experience lengthy circulation between several wholesalers and retailers before they are sold to final customers. However, in the e-commerce environment, the customers could buy the products either in the online retail stores of product manufacturers or in the network malls, which leads to the reduction of intermediate link, lower circulation costs and shorter distances between the companies and the customers. The companies could satisfy the habitual preferences of the customers quickly and provide personalized services due to direct feedbacks from customers through the internet [4].

Meanwhile, companies adopting B2C electronic commerce pattern could achieve competitive advantages which could be listed as follows [5].

1) Unlimited business hours. The network malls could provide consulting services, sales services, distribution services and other services 24 hours a day, 7 days a week.

2) Superior services. Unique services like cash on delivery and home delivery service meet diversified consumption demand of customers who pursuit personal development.

3) Lower price. The B2C companies are able to provide relatively lower price because 
they don't have to pay intermediate expenditures such as the fees for packaging products, advertising and leasing warehouses.

4) Richer products. Due to the infinite extension of the network resources, the exhibition room is large enough to show more diverse goods to customers, which makes up the space restrictions of actual retail stores.

5) Promptness and convenience. The network malls provide the customers with wonderful shopping experiences by offering convenient shopping platform and timesaving and efficient way of shopping.

\section{The Development of the B2C Electronic Commerce in China}

According to the historical statistics report released by the China Internet Network Information Center (CNNIC), the $\mathrm{B} 2 \mathrm{C}$ electronic commerce in China has undergone two stages of development [6].

The introductory stage of the $\mathrm{B} 2 \mathrm{C}$ electronic commerce. In this stage, both companies and consumers were exploring and learning how to use e-commerce system effectively. Related administration organizations were also in a learning situation on ecommerce system management. Banks, as another major participant of the e-commerce system, haven't set up safe and convenient online payment systems, either. The operation of the e-commerce system merely depended on the credibility of the major participants, while there were no any effective mechanisms to evaluate the integrity of the participants of economic activities in China at that time. Because of the lack of the personal integrity, the legitimate rights and interests of the participants could not be guaranteed at all. Due to the flooding of fake and inferior quality commodities, the consumers were short of sense of security when shopping online. As a result, the enterprises utility and customers utility in the $\mathrm{B} 2 \mathrm{C}$ electronic commerce pattern were reduced dramatically and the development of the $\mathrm{B} 2 \mathrm{C}$ electronic commerce in China was at a standstill.

The growth stage of the $\mathrm{B} 2 \mathrm{C}$ electronic commerce. During this period, the electronic commerce are managed mainly by Ministry of Commerce, changing from being managed jointly by Ministry of Information Industry (MII), Ministry of Foreign Trade and Economic Cooperation (MOFTEC), the People's Bank of China (PBOC), State Economic and Trade Commission (SETC), State Development Planning Commission (SDPC) and the State Administration of Industry and Commerce (SAIC). Soon afterwards, the Report of Chinese Electronic Commerce issued by Ministry of Commerce in 2004 establishes the guiding role of Ministry of Commerce in developing electronic commerce. In this stage, China have established reasonable systematic design and institution supply to bail the electronic commerce system out of the state of disorder and to promote the development of the $\mathrm{B} 2 \mathrm{C}$ electronic commerce pattern.

\section{The Four Patterns of the B2C Electronic Commerce}

\subsection{The E-commerce Direct Selling Pattern}

The e-commerce direct selling pattern refers to the pattern in which the product man- 
ufacturers directly sell product to the customers through their own e-commerce platforms. The traditional manufacturers set up their own online malls where the customers could buy products directly. In this operation pattern, the manufacturers have to equip with fully functional online sales platforms, professional information systems and business processes [1].

\subsubsection{Advantages}

1) Reputation guarantee. With the help of the reputation of the enterprises, the risks customers perceive are reduced, so trades could be facilitate smoothly.

2) Lower prices. The price of the products could be reduced largely for the reason that manufacturers are able to connect the customers directly. This pattern theoretically has least intermediate links in circulation.

3) Available after-sales services. The manufacturers could fully take advantage of traditional offline after-sales service systems to provide guarantees for the customers.

4) Personalized services. The product manufacturers could obtain first-hand consumer data and provide personalized services though the online malls.

5) Attainable make-to-order model. The manufacturers could produce products according to the online orders, so that they can control the inventory and cut loss.

\subsubsection{Disadvantages}

1) Soaring expenses are needed to construct, maintain and promote e-commerce platform.

2) The conflict exists between the online sales pattern and the traditional offline channels. Lower price in online sales pattern leads to a increasing number of customers shopping online, in turn a decreasing number of customers shopping through offline channels.

3) The product category provided by the manufacturers is limited, so the customers have to visit vast websites of different manufacturers to finish their purchase.

4) Limited influence of individual manufacturers makes them unable to get enough customer traffic, so the superiority of the e-commerce could not be reflected adequately.

\subsubsection{Case: The E-Commerce Direct Selling Pattern of Dell}

1) Introduction

Dell, a computer manufacturer, is a Fortune 500 company whose headquarter lies in Round Rock, Texas, America. Dell is known for producing, designing, selling personal computers and office computers. At the meanwhile, Dell also sets its feet in high-end computers, servers, data storage equipment, network equipment and other related products including PDA, software, printers.

2) The E-commerce Direct Selling Pattern of Dell

The success of Dell lies in its excellent service concepts, it have been maintaining ongoing communications with its customers directly and producing products based on the requirements of the customers. As for the pricing strategy, Dell sells its products at a lower price online than the products sold offline, which aims to bring the superiority 
of the online sales channel into full play and integrate its resources effectively. The reason why other manufacturers fail to copy the same patterns with Dell is that they could not succeed to resolve the conflicts between the online sales pattern and the traditional offline channels. For the reputation system, Dell is guaranteed by his own reputation. In terms of distribution system, Dell has outsourced all its logistic operations to the third party logistics enterprises which ensure free distribution of door within 5 days. What is more, the modes of payment Dell adopted is the mode of advance payment, including online payment, telegraphic transfer payment and city-wide payment. And its after-sales services systems depend on its offline after-sales service systems. With all these measures mentioned, Dell improves its business processes, reduces intermediate links in circulation and increases profits.

\subsection{The Integrated Middlemen Pattern}

The integrated middlemen pattern refers to the pattern in which the middlemen or retailers provide all kinds of products to the customers through the e-commerce platform [1]. The product manufacturers sell products to the third party trading platforms, such as the shopping websites. On the platforms, the shopping websites sell products of different manufacturers to purchasers.

\subsubsection{Advantages}

1) The third party trading platforms uniformly provide the delivery and after-sales services to the customers. And the good reputations of the websites and cash on delivery could reduce the risks that the customers perceive and increase the possibilities of trading.

2) It reduced intermediate links. Different with the traditional circulation patterns, this pattern no longer needs additional intermediate links such as the wholesalers and retailers. What's more, without additional fees like rentals, the costs could be greatly reduced.

\subsubsection{Disadvantages}

1) The e-commerce platforms require high traffic supports, so maintenance costs and promotion expense take up a large part of operation costs.

2) To maintain the diversity of product categories, the third party trading platforms have to stock enough products. In this case, a huge amount of inventory adds pressure to safe-keeping and storage, engages a considerable portion of manpower and facilities and aggravates the burden of the business.

3) Unable to compete with $\mathrm{C} 2 \mathrm{C}$ in the specific kind of commodity.

\subsubsection{Case: The Integrated Middlemen Pattern of Amazon}

1) Introduction

Amazon bookstore is an online bookstore with the biggest sales volume on a world scale. Amazon provides more than 3.1 million books online, which is almost fifteen times the stock of any other bookstores in the world. The e-commerce plays a key role in its success. It has been committed to marketing campaigns and service activities 
through the Internet.

2) The Integrated Middlemen Pattern of Amazon

The integrated middlemen pattern is the earliest B2C business model and Amazon is a typical representative of the integrated middlemen pattern in China. Amazon mainly focuses on the online bookstores and sells other 36 kinds of goods concurrently, such as home furnishings, digital products and mother \& baby products. Compared with the offline bookstores, Amazon provides bigger discounts for its customers, with 5\% - 40\% discounts. Due to its well-deserved reputation the risks that the customers perceive reduce largely. Amazon also cooperates with the third party logistic service providers to distribute products to doors in the major cities across China. As for the modes of payment, multiple modes of payment like online payment and cash on delivery are acceptable. Cash on delivery is a unique mode of payment which is inapplicable in the manufacturers' direct selling pattern and the third party trading platform pattern. Thanks to these effective measures, Amazon reduces its intermediate links in circulation and increases profits by sales online [7].

\subsection{The Vertical Middlemen Pattern}

The vertical middlemen pattern is similar with the integrated middlemen pattern in which retailers or middlemen interact with the customers. However, the vertical middlemen pattern concentrates on the specific market segment rather than the comprehensive market [1].

\subsubsection{Advantages}

1) In specific market segment, the vertical middlemen could provide more professional products and services to the customers.

2) In specific market segment, the vertical middlemen could provide more favorable price.

3) The vertical middlemen concentrate on the specific market segment, so the brand cognitive of the websites is higher.

\subsubsection{Disadvantages}

1) The costs for maintenance and promotion of the e-commerce platforms are high.

2) The credibility systems are far from impeccable. The complexity of the remote transaction requires nationwide credibility systems built by the government or the third parties.

\subsubsection{Case: The Vertical Middlemen Pattern of Jingdong Mall}

1) Introduction

The Jingdong Mall is one of the classic cases of the vertical middlemen pattern. Richard Liu founded the Jingdong Company in the Zhongguancun. In 2001, Jingdong has become the most influential agent for the light magnetic products. In 2004, Jingdong took its first step into the e-commerce by setting up the Jingdong multimedia network. According to its official website, there are more than 60 million registered users and 
nearly ten thousand suppliers in Jingdong mall. The quantity of the orders processed of the Jingdong mall exceeds 500,000 every day.

2) The Vertical Middlemen Pattern of the Jingdong Mall

The rapid growth of the Jingdong Mall owe to several elements, which is listed as follows.

a) Lower operating costs. Compared with Suning and Gome, Jingdong could save a large amount of store rents because it did not have outlets.

b) Lower financial costs due to the advanced operational efficiency of logistics, information flows and capital flows.

c) The brand effects and superior user experiences. While the quality of products in Taobao varies, the products sold in the Jingdong Mall are almost mature brand products. Thus the Jingdong Mall wins the trusts of the online customers. The Jingdong Mall also provides services including "arrive in limited time", "compensation in advance" and "delivery to your door" to improve user experiences and build brand loyalty.

d) Jingdong Mall speeds up its inventory turnover by having the self-built logistics. With the help of the self-built logistics, the Jingdong Mall could manage its logistics well, form its own distribution service standards and improve the user's shopping experiences. The lower price and perfect delivery services contribute to its brand public praise.

\subsection{The Third Party Trading Platform Pattern}

Essentially, the third party trading platform is a credit guaranteed information intermediary platform. The websites provide platform for the manufacturers and middlemen to serve the customer, but the websites itself doesn't engage in the delivery and after-sales services. This pattern requires the high profiles, high click rates and high traffics of the trading platforms. The main difference between the pattern and the $\mathrm{C} 2 \mathrm{C}$ business model of the small and medium-sized enterprises is that the $\mathrm{C} 2 \mathrm{C}$ trading platforms can't assure the qualities of its products while the third party trading platforms assure the qualities of products through its brands reputation and the strict access systems [1].

\subsubsection{Advantages}

1) Relative safety. The information of credit card or account is merely told to the payment intermediation rather than every payee involved, thus the risks of disclosing the key information could be reduced greatly.

2) Lower payment costs. The payment intermediation reduces the payment costs by collecting a large number of small electronic trading and forming the scale effect.

3) Easy use. The payers need not concerning themselves with the complex technical operation process. They face a user-friendly interface instead.

4) The payment guaranteed businesses can ensure the interests of the payers to a great degree. 


\subsubsection{Disadvantages}

1) The sellers of the B2C business model have to pay a fee to the third party trading platforms, so the commodity price of the $\mathrm{B} 2 \mathrm{C}$ sellers is higher than the $\mathrm{C} 2 \mathrm{C}$ sellers on the same platform inevitably. For the online customers who are sensitive to the price, it is a fatal flaw of $\mathrm{B} 2 \mathrm{C}$ business model.

2) The classification and amount of the commodities of the B2C business model are significantly less than those of $\mathrm{C} 2 \mathrm{C}$ business model.

3) The sellers of the B2C malls are the manufacturers or entity dealers normally. It is difficult for them to interact with each customer while selling the non-standard goods such as clothing and food which requires the interactions between the sellers and the buyers to reduce the risks that the customers perceive and increase the possibilities of trading. At the moment, the $\mathrm{B} 2 \mathrm{C}$ business model is unable to improve that.

\subsubsection{Case: The Third Party Trading Platform Pattern of the Taobao Mall}

1) Introduction

As the predecessor of Tmall, the Taobao Mall, founded in April, 2008 is the channel connecting enterprises and consumers. As the Taobao Mall become increasingly successful, increasing number of famous brands from home and abroad open their official flagship stores on this platform. The Taobao Mall was separated from Taobao in June, 2011 to increase the brand awareness and separate the $\mathrm{B} 2 \mathrm{C}$ companies from the $\mathrm{C} 2 \mathrm{C}$ sellers of Taobao. At present, the Taobao Mall sells products of 30,000 brands from home and abroad and has several vertical malls for different industries, such as circuit city, shoes pavilion and clothing pavilion. The Taobao Mall was renamed as Tmall at January 11, 2012.

2) The Third Party Trading Platform Pattern of the Taobao Mall

The Taobao Mall is a typical third party trading platform for the enterprises and the consumers, but the Taobao Mall doesn't engage in the sales and after-sales services. The sellers take charge of their sales, delivery and after-sales services themselves, thus the operation costs of the Taobao Mall could be reduced greatly.

The Taobao Mall takes advantage of the B2C business model to solve the defects of credit systems in C2C business model. Due to the loose access systems and the defects of credit systems in $\mathrm{C} 2 \mathrm{C}$ business model, the $\mathrm{C} 2 \mathrm{C}$ trading plat forms could not guarantee the quality of the goods and avoid the fakes. The Taobao Mall guarantees the qualities of the goods though strict access systems and the joint reputations of the Taobao Mall and companies. The Taobao Mall charges for the access fees and provides the additional fee-based services to the companies to make profits.

\section{Suggestions for Development of the B2C E-Commerce in China}

As for the enterprise management, the following strategies can be used by companies involved in the $\mathrm{B} 2 \mathrm{C}$ e-commerce, which is listed as follows [8].

1) Formulating appropriate corporations strategies.

2) Strengthening the information management. 
3) Coordinating marketing channels.

4) Strengthening the transaction pricing management.

As for the industry development, the retail industry online should speed up information construction, which is described in detail as follows [9].

1) Speeding up the flow of information within companies through the internet.

2) Strengthening the function of channels. Apart from the original traditional shops, the enterprises should open up new sales channels on the internet.

3) Integrating the value chains and the supply chains to make full preparation for new technologies and to realize effective \& efficient operations.

4) Providing related services online in addition to physical goods to make the products more personalized and more attractive.

Several traditional sales planning and skills could be transplanted into the online businesses [10]. Some sales planning and skills of certain commodities are more suitable for online uses, they deserves applying to increase conversion rates, such as the books and DVDs industry.

Offer favorable information query and comparison tools for commodity. On a B2C e-commerce website, the customers demand a friendly interface tool to search commodity information they require and to compare different commodities quickly and easily. In that case, the customers feel as comfortable as shopping in the entity stores.

Pay attention to the rank of the promotional commodities shown online. Doubts about the qualities of the online commodities and concerns about the safety of the online consumption lead to the tentative consumption of the online customers. In this case, the e-commerce companies should exhibit the economical and traditional goods at first to reduce the risks that the customers perceive.

The e-commerce companies could offer personalized and highly interactive services to allow the consumers to experience the shopping environment of virtual reality. The techniques such as 3D online games, BBS, topic news and pop music could be used to create online shopping atmosphere, improve the popularity and facilitate the consumption.

The e-commerce companies could build the virtual dressing rooms to combine the entity stores and the online malls [11]. The 3D technology is worth trials to create a three dimensional shopping environment and increase personalization and interactivity in the process of consumption.

\section{References}

[1] Liu, Z.-L. (2009) A Comparative Study of B2CBusiness Model. E-business Journal, No. 1, 55-59.

[2] Liang, J.-K., Jin, X. and Hao, M.-C. (2007) A Study of the Advantages and Disadvantages of B2C Electronic Commerce Pattern. Market Modernization, No. 7, 94.

[3] Liang, J.-L. and Peng, L. (2014) An Analysis of B2C E-Commerce Model in Tmall, Jingdong and VANCL. Journal of Wuhan Engineering Institute, No. 2, 52-56.

[4] Xi, W. and Rong, F. (2000) An Analysis on the E-Commerce of B2B and B2C on the View of the Value Chain-And Measures of Our Enterprises to Carry out E-commerce. Journal 
of Tsinghua University (Philosophy and Social Sciences), No. 4, 72-76.

[5] Chen, X. (2010) An Analysis on the Problems in Development of Enterprises under the B2C E-Commerce Model. Science \& Technology Information, 32, 143.

[6] Tao, H. and Ye, G.-C. (2007) The Development Process of the B2C Electronic Commerce Pattern in China. Commercial Times, No. 1, 79-80.

[7] Ling, Y. and Qian, Y. (2009) A Study of the Innovation of the RegionalB2C Electronic Commerce Pattern Based on Unified Distribution. China Management Informationization, No. 1, 97-100.

[8] Lin, D.-M. and Fan, L. (2001) The Comparison and Analysis of the B2C E-Commerce Model. Forward Position in Economics, Z1, 92-94.

[9] Luo, H.-Y. (2004) The Analysis and Suggestions of the B2C E-Commerce Model. Journal of Information, No. 2, 10-12.

[10] Li, Z.-M. and Zhang, L. (2008) A Study of the Advantages and Development Strategies of the B2C E-Commerce. HLJ Foreign Economic Relations \& Trade, 11, 88-89.

[11] Mao, X.-T. (2014) A Study of the Problems and Solutions of the B2C E-Commerce Model in China. Inner Mongolia Statistics, No. 2, 15-18.

\section{Submit or recommend next manuscript to SCIRP and we will provide best service for you:}

Accepting pre-submission inquiries through Email, Facebook, LinkedIn, Twitter, etc.

A wide selection of journals (inclusive of 9 subjects, more than 200 journals)

Providing 24-hour high-quality service

User-friendly online submission system

Fair and swift peer-review system

Efficient typesetting and proofreading procedure

Display of the result of downloads and visits, as well as the number of cited articles

Maximum dissemination of your research work

Submit your manuscript at: http://papersubmission.scirp.org/

Or contact jissm@scirp.org 